were bought during the last 20 years.

Public shows are carried out by tape; 10 to 12 special lectures per year are given by foreign astronomers. Most demonstrations for pupils are live. Occasionally we have music performances.

Stuttgart Planetarium: Stuttgart, the capital of the German Federal State Baden-Württemberg, the Swabian metropole, was one of the first cities to have a major planetarium. It was opened in 1928 and destroyed in 1943. In April 1977, the new Stuttgart Planetarium was opened. The Carl Zeiss Company donated a Mark IV projector and additional financial support toward the cost of the building. It was the first planetarium in Germany with a fully automatic control system. The Zeiss-projector can be lowered under the floor with an elevator. In the first ten years, more than 2 million visitors came to the star performances. Besides shows for the general public, we give live presentations for school and special groups. About 50 per cent of the visitors are students and scholars. The full-time staff of eleven persons is supported by 21 part-time workers. The main tasks of our planetarium are to teach astronomy for the general public and for advanced students, too, and to demonstrate how small our blue planet is - a tiny island of life in the giant, deep, boundless universe - and that the fate of mankind depends on skilled behavior of all human beings for living in peace and freedom.

\title{
Marketing for Planetariums
}

\section{J.V. Feitzinger}

Observatory of the City of Bochum and Astronomical Institute, Ruhr-University, Postfach 10 2148, D-4630 Bochum 1, Federal Republic of Germany.

The sales promotion of the planetarium is a marketing problem. Program arrangements must take this into account. Marketing is not exclusively a tool to obtain a maximum profit: marketing methods can control the exchange problems between the public and the nonprofit planetarium. The planetarium produces a service. This service must be distributed to the public. The public must know that the planetarium distributes a special service.

The public visits the planetarium during leisure time. (One exception - the school classes - is not considered here.) Therefore one marketing problem of the planetarium is to sell its service as recreational value.

The leisure time activities of the public can be divided into 10 categories. These categories contain the basic patterns and needs of the public. The content of the public planetarium performances must try to cover the leisure-time categories. The communication windows of the public can only be reached by simplifying astronomical facts. 
Table 1 . The planetarium as a leisure time activity

Leisure time categories met by

Planetarium visits

$\begin{array}{ll}\text { 1. Physical movement; } & \begin{array}{l}\text { No correspondence } \\ \text { sporting - playful activities }\end{array} \\ \text { (sporting activities) }\end{array}$

2. Calmness, loneliness, All planetarium performances self-realization also pure music and star presentations

3. Social life and social Planetarium visits by groups and communication the resulting conversations

4. Social presentation Technical and scientific interests; status thinking

5. Amusement and dissemination Planetarium performances are ideal; not much own initiative, diversion

6. Intellectual and political interests, discussion, Planetarium performances are well suited education

7. Mobility, search for new environment attractions

In the course of planetarium performances: Presentation of realistic planetary or science-fiction environments

8. Participations at Astroquiz competitions, achievement, rivalry

9. Playful pastimes, not

Similar to point 5 (the determined by its function boundaries are flowing)

10. Well-being, sensual impressions

Similar to point 5 (especially music performances)

The planetarium is a versatile institution that fits well into the leisure-time categories of the public. There should be no exchange difficulties, if these categories are taken into account in the program. 